\title{
Possibility of Undifferentiated Human Thigh Adipose Stem Cells Differentiating into Functional Hepatocytes
}

\author{
Jong Hoon Lee ${ }^{1,2}$, Kuk Han Lee ${ }^{1}$, Min Ho Kim ${ }^{2,3}$, Jun Pyo Kim${ }^{4}$, Seung Jae Lee ${ }^{4}$, Jinah Yoon ${ }^{5}$ \\ ${ }^{1}$ Department of Plastic and Reconstructive Surgery, Eulji General Hospital, Eulji University College of Medicine; ${ }^{2}$ Eulji Medi-Bio Research \\ Institute, Eulji University; ${ }^{3}$ Division of Biotechnology, College of Life Sciences and Biotechnology, Korea University; ${ }^{4}$ CL Aesthetic Clinic; \\ ${ }^{5}$ Department of Biotechnology, Seoul Women's University, Seoul, Korea
}

Background This study aimed to investigate the possibility of isolating mesenchymal stem cells (MSCs) from human thigh adipose tissue and the ability of human thigh adipose stem cells (HTASCs) to differentiate into hepatocytes.

Methods The adipose-derived stem cells (ADSCs) were isolated from thigh adipose tissue. Growth factors, cytokines, and hormones were added to the collagen coated dishes to induce the undifferentiated HTASCs to differentiate into hepatocyte-like cells. To confirm the experimental results, the expression of hepatocyte-specific markers on undifferentiated and differentiated HTASCs was analyzed using reverse transcription polymerase chain reaction and immunocytochemical staining. Differentiation efficiency was evaluated using functional tests such as periodic acid schiff (PAS) staining and detection of the albumin secretion level using enzyme-linked immunosorbent assay (ELISA).

Results The majority of the undifferentiated HTASCs were changed into a more polygonal shape showing tight interactions between the cells. The differentiated HTASCs up-regulated mRNA of hepatocyte markers. Immunocytochemical analysis showed that they were intensely stained with anti-albumin antibody compared with undifferentiated HTASCs. PAS staining showed that HTASCs submitted to the hepatocyte differentiation protocol were able to more specifically store glycogen than undifferentiated HTASCs, displaying a purple color in the cytoplasm of the differentiated HTASCs. ELISA analyses showed that differentiated HTASCs could secrete albumin, which is one of the hepatocyte markers.

Conclusions MSCs were islolated from human thigh adipose tissue differentiate to heapatocytes. The source of ADSCs is not only abundant abdominal adipose tissue, but also thigh adipose tissue for cell therapy in liver regeneration and tissue regeneration.

Keywords Thigh / Adipose tissue / Stem cells / Hepatocytes / Cell Differentiation
Correspondence: Jong Hoon Lee Department of Plastic and Reconstructive Surgery, Eulji General Hospital, Eulji University School of Medicine, 68 Hangeulbiseong-ro, Nowon-gu, Seoul 139-711, Korea

Tel: $+82-2-970-8255$

Fax: +82-2-978-4772

E-mail: joaljh@eulji.ac.kr

This article was presented as a poster at the 69th Congress of the Korean Society of Plastic and Reconstructive Surgeons on November 11-13, 2011 in Seoul, Korea.

No potential conflict of interest relevant to this article was reported.

\section{INTRODUCTION}

The liver is one of the most important organs for the survival of living organisms. It performs a wide range of functions including detoxification, protein synthesis, and the production of numer- ous biochemicals. Malfunction or dysfunction of hepatocytes leads, in many cases, to incurable liver diseases. Until now, orthotopic liver transplantation has been the only available treatment for patients with end-stage liver diseases. However, the use of this procedure is limited by the availability of donor organs. Hepato-

Copyright $\odot 2012$ The Korean Society of Plastic and Reconstructive Surgeons

This is an Open Access article distributed under the terms of the Creative Commons Attribution Non-Commercial License (http://creativecommons.org/

licenses/by-nc/3.0/) which permits unrestricted non-commercial use, distribution, and reproduction in any medium, provided the original work is properly cited.

www.e-aps.org 
cyte transplantation could be employed as an alternative therapeutic approach to whole liver transplantation for liver failure. Recent studies have suggested that stem cell-derived hepatocytes could be utilized as therapeutic hepatocytes [1-5].

Bone marrow-derived mesenchymal stem cells (BM-MSCs), which possess characteristics such as self-renewal, pluripotency, proliferation, longevity, and differentiation, could be one of the sources for transplantable and therapeutic cells $[6,7]$. However, traditional bone marrow procurement procedures may be distressing to patients and yield a low number of MSCs when performed. Therefore, many researchers have investigated alternative stem cell sources for replacing BM-MSCs.

Adipose tissue commonly obtained using liposuction during plastic surgery is an attractive source of human MSCs, because it is a safe and abundant tissue in the body compared with other tissues. The stem cells in adipose tissue that are capable of differentiating into functional hepatocyte-like cells have phenotypic characteristics similar to BM-MSCs $[8,9]$. Several studies have reported the differentiation of hepatocyte-like cells from human adipose tissue-derived mesenchymal stem cells [1-3]. Seo et al. [4] demonstrated for the first time that human adipose tissue-derived mesenchymal stem cells differentiate into hepatocyte-like cells upon treatment with a hepatocyte growth factor (HGF), oncostatin M (OSM), and dimethyl sulfoxide (DMSO). These cells expressed albumin (ALB), $\alpha$-fetoprotein (AFP), and other hepatocyte-specific markers during hepatic differentiation and increased in low-density lipoprotein (LDL)uptake and urea production. In most of the reports on adiposederived stem cells (ADSCs), the source of the adipose tissue used has been abundant abdominal adipose tissue. However, thigh adipose tissue that is commonly obtained using liposuction in plastic surgery can also be used as a source of ADSCs.

In this study, MSCs were isolated from human thigh adipose tissue and characterized for morphology, growth potency, phenotypic profile, and the capacity of differentiating into hepatic lineages. In addition, the ability of human thigh adipose stem cells (HTASCs) to differentiate into hepatocytes was evaluated.

\section{METHODS}

\section{Hepatic differentiation protocol}

Passages of 3 to $7.5 \times 10^{3}$ cells were plated onto a collagen coated 48-well culture plate, and hepatic differentiation was then performed over a period of three weeks using a three-step protocol (Fig. 1). At step I for the initiation, the cells were cultured for 4 days in serum-deprived Dulbecco's modified Eagle's medium with high glucose (DMEM-HG) supplemented with $100 \mu \mathrm{M} \mathrm{L}$ ascorbic acid 2-phosphate (Asc 2-P) and $1 \times$ insulin-transferrinselenium (ITS) consisting of $10 \mathrm{mg} / \mathrm{mL}$ insulin, $0.55 \mu \mathrm{g} / \mathrm{mL}$ transferrin, $0.67 \mu \mathrm{g} / \mathrm{mL}$ sodium selenite, $50 \mathrm{ng} / \mathrm{mL}$ activin $\mathrm{A}$, and $20 \mathrm{ng} / \mathrm{mL}$ fibroblast growth factor 4 (FGF4). At step II for the induction, they were cultured for 7 days in DMEM with low glucose (LG) supplemented with $10 \%$ fetal bovine serum (FBS), $100 \mu \mathrm{M}$ A2P, $1 \mu \mathrm{M}$ dexamethasone, $10 \mathrm{mM}$ nicotinamide, and $1 \times$ ITS consisting of $20 \mathrm{ng} / \mathrm{mL} \mathrm{HGF,} 20 \mathrm{ng} / \mathrm{mL}$ FGF4, $20 \mathrm{ng} / \mathrm{mL}$ epidermal growth factor (EGF), and $20 \mathrm{ng}$ / mL OSM. During step III for the maturation, the cells were treated with DMEM-LG supplemented with 10\% FBS, $100 \mu \mathrm{M}$ Asc 2-P, $20 \mathrm{ng} / \mathrm{mL}$ OSM, $1 \mu \mathrm{M}$ dexamethasone, 1\% DMSO, and $1 \times$ ITS for 7 days.

\section{Reverse transcription-polymerase chain reaction}

Total RNA was isolated from undifferentiated or differentiated HTASCs using RNAiso kit (Takara, Otsu, Japan). The amount of RNA was assessed by measuring the ratio of absorbance at 260 $\mathrm{nm}$ to that at $280 \mathrm{~nm}(>1.8)$. Reverse transcription polymerase chain reaction (RT-PCR) was carried out using a thermal cy-

\section{Fig. 1. The steps of differentiation}

The steps of human thigh adipose stem cells differentiation into hepatocytes. FGF4, fibroblast growth factor 4; DMEM-HG, Dulbecco's modified Eagle's medium with high glucose; FBS, fetal bovine serum; Asc 2-P, L-ascorbic acid 2-phosphate; ITS, insulin-transferrin-selenium; HGF, hepatocyte growth factor; EGF, epidermal growth factor; OSM, oncostatin M; DMSO, dimethyl sulfoxide.

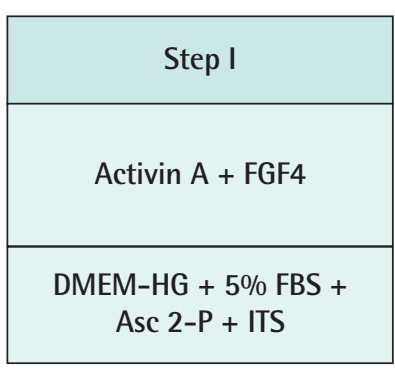

3-4 days

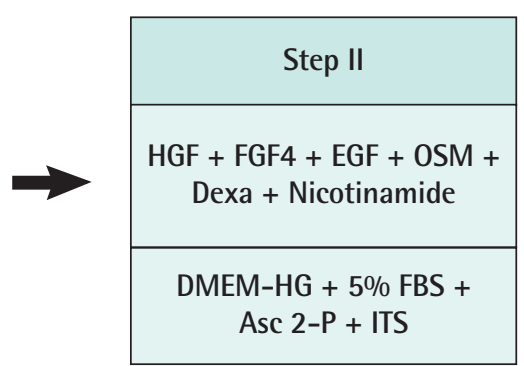

7 days

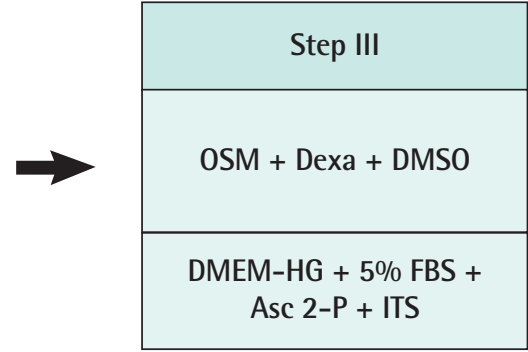

7 days 
cler (GeneAmp PCR system 2400, Perkin-Elmer, Boston, MA, USA). A total of $7.5 \mu \mathrm{g}(1 \mu \mathrm{g} / \mu \mathrm{L})$ RNA was reverse-transcribed using the following RT mixture: $25 \mathrm{mM} \mathrm{MgCl}_{2}, 10 \times \mathrm{PCR}$ buffer, $2.5 \mathrm{mM}$ dNTPs mixture, $0.5 \mathrm{mg} / \mathrm{mL}$ oligo $(\mathrm{d}) \mathrm{T}^{15}$, 40 U RNase inhibitor, and $20 \mathrm{U}$ AMV-RT. The RT reaction was allowed to occur for 60 minutes at $42^{\circ} \mathrm{C}$, and the resultant cDNA was sub- jected to PCR amplification, using upstream and downstream primers of hepatocyte-specific genes as shown in Table 1. PCR was performed using the following PCR mixture: $25 \mathrm{mM} \mathrm{MgCl}_{2}$, $10 \times$ PCR buffer, $2.5 \mathrm{U}$ Thermus aquaticus (Taq) polymerase, and $100 \mathrm{pM}$ sense and antisense primers. Amplification was performed for 35 cycles. Annealing temperature was depending

\section{Table 1. Primers used for the RT-PCR analysis for the stem cells and hepatocyte-related genes}

\begin{tabular}{|c|c|c|c|c|}
\hline Gene & Primer sequence & Size (bp) & Temp $\left({ }^{\circ} \mathrm{C}\right)$ & Accession number \\
\hline \multirow[t]{2}{*}{ SCF } & 5'-CCA TTG ATG CCT TCA AGG AC-3' & & & \\
\hline & 5'-CTT CCA GTA TAA GGC TCC AA-3' & 275 & 55 & M59964 \\
\hline \multirow[t]{2}{*}{ Oct4 } & 5'-CGT GAA GCT GGA GAA GGA GAA GCT G-3' & & & \\
\hline & 5'-CAA GGG CCG CAG CTC ACA CAT GTT C-3' & 245 & 55 & AF268617 \\
\hline \multirow[t]{2}{*}{ Nanog } & 5’-ATG GCT ATG TGT GCT ATG AGC-3’' & & & \\
\hline & 5'-CCT CAA CTT CTA GTG CAT CC-3' & 331 & 55 & NM_174900 \\
\hline \multirow[t]{2}{*}{ Vimentin } & 5'-CCT TCG TGA ATA CCA CG ACCT GC-3' & & & \\
\hline & 5'-TAA TAT ATC GCC TGC CAC TGA G-3’ & 321 & 56 & Z19554 \\
\hline \multirow[t]{2}{*}{ CK18 } & 5'-GAG ATC GAG GCT CTC AAG GA-3' & & & \\
\hline & 5'-CAA GCT GGC CTT CAG ATT TC-3' & 357 & 57 & NM_00024 \\
\hline \multirow[t]{2}{*}{ FGF-5 } & 5'-GCT GTG TCT CAG GGG ATT GTA GGA ATA-3' & & & \\
\hline & 5'-TAT CCA AAG CGA AAC TTG AGT CTG TA-3' & 434 & 55 & NM_004464 \\
\hline \multirow[t]{2}{*}{ NCAM } & 5'-GAG GGG GAA GAT GCC GTG ATG TG-3' & & & \\
\hline & 5'-ATA TTC TGC CTG GCC CGG ATG GTA G-3' & 269 & 60 & NM_000615 \\
\hline \multirow[t]{2}{*}{ Pax6 } & 5'-AGA TTC AGA TGA GGC TCA AA-3' & & & \\
\hline & 5'-AAT TGG TTG GTA GAC ACT GG-3' & 313 & 57 & AY707088 \\
\hline \multirow[t]{2}{*}{ BMP4 } & 5'-AGC CAT GCT AGT TTG ATA CC-3' & & & \\
\hline & 5'-TCA GGG ATG CTG CTG AGG TT-3' & 383 & 55 & D30751 \\
\hline \multirow[t]{2}{*}{ BMP2 } & 5'-TTG CGG CTG CTC AGC ATG TT-3' & & & \\
\hline & 5'-TTG CGA GAA CAG ATG CAA GAT G-3' & 315 & 55 & BC069214 \\
\hline \multirow[t]{2}{*}{ HNF4 $\alpha$} & 5'-GAG CAG GAA TGG GAA GAA TG-3' & & & \\
\hline & 5'-GGC TGT CCT TTG GGA TGA AG-3' & 205 & 62 & NM_178849 \\
\hline \multirow[t]{2}{*}{ HLA-ABC } & 5'-GTA TIT CTT CAC ATC CGT GTC CCG-3' & & & \\
\hline & 5'-GTC CGC CGC GGT CCA AGA GAG CAG-3' & 394 & 70 & L18898 \\
\hline \multirow[t]{2}{*}{ HLA-DR } & 5'-CTG ATG AGC GCT CAG GAA TCA TGG-3' & & & \\
\hline & 5'-GAC TTA CTT CAG TTT GTG GTG AGG GAA G-3' & 220 & 60 & X06079 \\
\hline \multirow[t]{2}{*}{ AFP } & 5'-GTG CTG CAC TTC TTC ATA TGC-3' & & & \\
\hline & 5'-TGA CAG CCT TCA AGT TGT TCC-3' & 218 & 54 & NM_001134 \\
\hline \multirow[t]{2}{*}{ ALB } & 5'-TTG GGA GAA GAA AAT TTC AA-3' & & & \\
\hline & 5'-TAT ACC TTा TAG CAA AGA AAA GGA-3' & 445 & 49 & NM_001875 \\
\hline \multirow[t]{2}{*}{ CX32 } & 5'-GGC GTG AAC CGG CAT TCT AC-3' & & & \\
\hline & 5'-ACA ACA GCC GGA ACA CCA CG-3' & 400 & 61 & NM_000166 \\
\hline \multirow[t]{2}{*}{ Trans-ferrin } & 5'-GTG GCC TTT GTC AAG CA-3' & & & \\
\hline & 5'-CTC CAT CCA AGC TCA TG-3' & 565 & 52 & NM_001013 \\
\hline \multirow[t]{2}{*}{ UGT1A1 } & 5'-GTA CCA TTC CTT GGA CGT GAT T-3' & & & \\
\hline & 5'-TAC ACC ACC CAC CAA ATT TCA TA-3' & 745 & 59 & NM_000463 \\
\hline \multirow[t]{2}{*}{ CYP2B6 } & 5'-GGC ACA CAG GCA AGT TTA CA-3' & & & \\
\hline & 5'-CCA GCA AAG AAG AGC GAG AG-3' & 210 & 62 & NM_000767 \\
\hline \multirow[t]{2}{*}{ CAR } & 5'-CAG CAA ACA CCT GTG CAA CTG-3' & & & \\
\hline & 5'-AAG GGC TGG TGA TGG ATG AA-3' & 146 & 59 & NM_001077482 \\
\hline \multirow[t]{2}{*}{ CK18 } & 5'-GAG ATC GAG GCT CTC AAG GA-3' & & & \\
\hline & 5'-CAA GCT GGC CTT CAG ATT TC-3' & 357 & 57 & NM_000224 \\
\hline \multirow[t]{2}{*}{ HNF1 $\alpha$} & 5'-CAG TCT TCT TAC TTG GAA CTG AA-3' & & & \\
\hline & 5'-CT GGG AAC AAA TAC AGG AA-3' & 444 & 54 & NM_000545 \\
\hline $\mathrm{HNF} 4 \alpha$ & 5'-GAG CAG GAA TGG GAA GGA TG-3' & & & \\
\hline & 5'-GGC TGT CCT TTG GGA TGA AG-3' & 205 & 60 & NM_178849 \\
\hline GAPDH & 5'-ACA ACT TTG GTA TCG TGG AA-3' & & & \\
\hline & 5'-AAA TTC GTT GTC ATA CCA GG-3' & 456 & 53 & NM_002046 \\
\hline
\end{tabular}


on the species of primers. The PCR products were mixed with $6 \times$ loading buffer $(0.25 \%$ bromophenol blue, $0.25 \%$ xylene cyanol, and $40 \%$ sucrose) and separated on $2 \%$ agarose gels. After electrophoresis, the gels were stained with ethidium bromide. DNA signals on the gel were imaged under ultraviolet light using a Bioprofile Image Analysis System (UV Viewing Cabinet, Vilber Lourmat, Marne la Vallee, France).

\section{Immunocytochemical analysis}

The immunophenotype of the cells was determined using a stain kit (Vector Laboratory, Burlington, CA, USA) according to the manufacturer's instructions. After the cells were cultured onto 8-well culture dishes, they were washed with Dulbecco's phosphate buffered saline (DPBS) three times and fixed with $4 \%$ paraformaldehyde in phosphate buffered saline (PBS) for 1 hour at $4^{\circ} \mathrm{C}$. They were washed with PBS and then permeabilized with $0.5 \%$ Triton X-100 in DPBS for 10 minutes at room temperature. After several washings, the cells were incubated in 3\% hydrogen peroxide for 15 minutes to quench the endogenous peroxidase activities. They were then rinsed with DPBS and incubated in a blocking solution containing $2.5 \%$ horse serum for 30 minutes at room temperature with gentle shaking. The cells were incubated with mouse monoclonal antibodies against human albumin (ALB, 1:100), which had been diluted in $0.5 \%$ horse serum. After incubation with the primary antibodies for 17 hours at $4^{\circ} \mathrm{C}$ with gentle shaking, the cells were washed and rinsed with DPBS. They were incubated with a biotinylated universal antibody horse anti-rabbit/mouse IgG for 30 minutes at room temperature. The cells were rinsed several times, and then incubated with avidin-biotin complex $(\mathrm{ABC})$ reagent conjugated streptavidin for 10 minutes at room temperature. Immunoreactivity was visualized utilizing 3,3'-diaminobenzidine tetrahydrochloride (DAB). The color reaction was stopped with water. Finally, they were counterstained with Mayer's hematoxylin for 1 minute, and then observed under a light microscope (Zeiss, Oberkochen, Germany).

\section{Albumin secretion by enzyme-linked immunosorbent assay (ELISA)}

After 18 days of culture in hepatocyte differentiation media, the cells were transferred to starvation media deprived of serum, and the supernatant was harvested 20 hours later. The human albumin concentration in the supernatant was determined using the Human Albumin ELISA Quantitation Kit (Exocell Inc., Philadelphia, PA, USA) according to the manufacturer's instructions. Serial dilution of a stock solution of albumin was used to create a standard curve. Samples were analyzed in duplicate under each condition.

\section{Periodic acid schiff(PAS) staining of glycogen deposits}

To visualize cellular deposits of glycogen molecules, cultured cells were fixed in 4\% paraformaldehyde in PBS for 1 hour at $4^{\circ} \mathrm{C}$ and rinsed with PBS several times. They were permeabilized with $0.1 \%$ Triton X-100 in PBS for 10 minutes. The cells were then oxidized in periodic acid for 20 minutes at room temperature and rinsed three times in deionized $\mathrm{H}_{2} \mathrm{O}\left(\mathrm{dH}_{2} \mathrm{O}\right)$. After treating the cells with $0.5 \%$ sodium bisulfite in $0.05 \mathrm{~N}$ $\mathrm{HCl}$ for 10 minutes, the cells were counterstained with Mayer's hematoxylin for 1 minute, rinsed in $\mathrm{dH}_{2} \mathrm{O}$, and observed for the purple staining indicative of the presence of glycogen using a light microscope.

\section{Statistical analysis}

Statistical analyses of this data were performed using the t-test. P-values $<0.05$ were considered statistically significant. All results were derived from at least three independent experiments.

\section{RESULTS}

\section{In vitro differentiation of HTASCs into hepatocyte-like cells}

Growth factors, cytokines, and hormones were added to the collagen coated dishes to induce the undifferentiated HTASCs to differentiate into hepatocyte-like cells. During step I for initiation, cell morphology was not greatly changed by the treatment of activin A and FGF4 in the serum-deprived media. When the

\section{Fig. 2. Morphological features}

Morphological features following the steps of hepatogenic-differentiated human thigh adipose stem cells $(\times 100)$. In stage II, the cells' morphology was gradually changed to a round or polygonal shape. The majority of the cells were changed into a more polygonal shape showing tight interactions between the cells. (A) Human thigh adipose stem cells (0 day), (B) Stage I (4 days), (C) Stage II (11 days), and (D) Stage III (18 days).
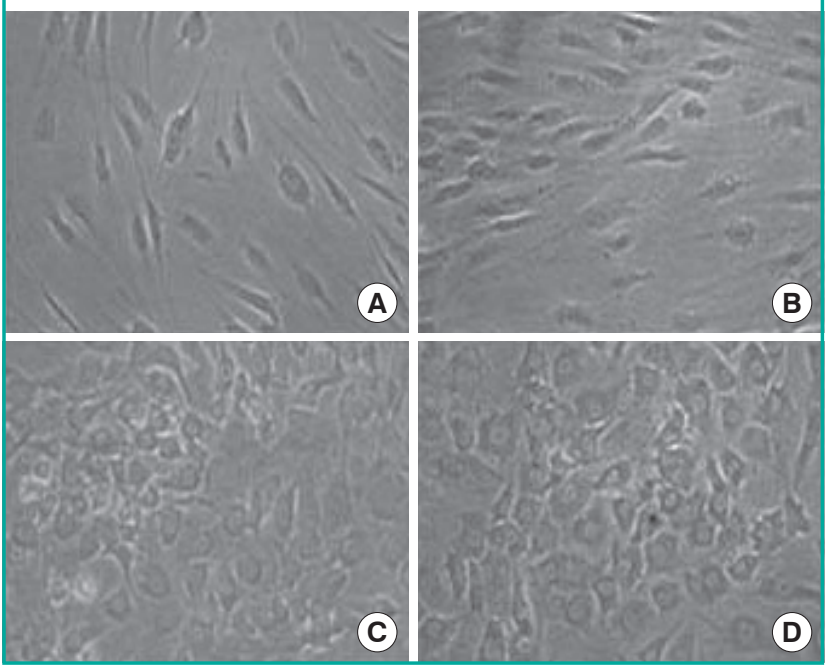
cells were cultured in the step II media containing HGF, OSM, and dexamethasone for 7 days, the cells gradually changed from a fibroblast-like morphology to a round or polygonal shape. Finally, the cells were cultured in the step III media including OSM, dexamethasone, and DMSO for more than 7 days for maturation; the majority of the cells changed into a more polygonal shape showing tight interactions between the cells (Fig. 2).

\section{Gene expression patterns of HTASC-derived hepato- cyte-like cells}

To confirm the above results, the expression of hepatocytespecific markers on undifferentiated and differentiated HTASCs was analyzed using RT-PCR and immunocytochemical staining. Undifferentiated cells expressed mRNA for CK18, HNF1 $\alpha$, and HNF4 $\alpha$, but not ALB, CX32, transferrin, UGT1A1, CYP2B6, or CAR. In contrast, differentiated HTASCs expressed or up-regulated mRNA for ALB, CX32, transferrin, UGT1A1, CYP2B6, CAR, CK18, HNF1 $\alpha$, and HNF4a (Fig. 3). Immunocytochemical analysis showed that they were intensely stained with an anti-albumin antibody compared with undifferentiated

\section{Fig. 3. The expression of hepatocyte-specific markers}

Expression of hepatocyte-specific markers on undifferentiated (C) and differentiated (Hepa) human thigh adipose stem cells; (Hepa) expressed or up-regulated mRNA for albumin (ALB), CX32, transferrin, UGT1A1, CYP2B6, CAR, CK18, HNF1 $\alpha$, and HNF4 $\alpha$.

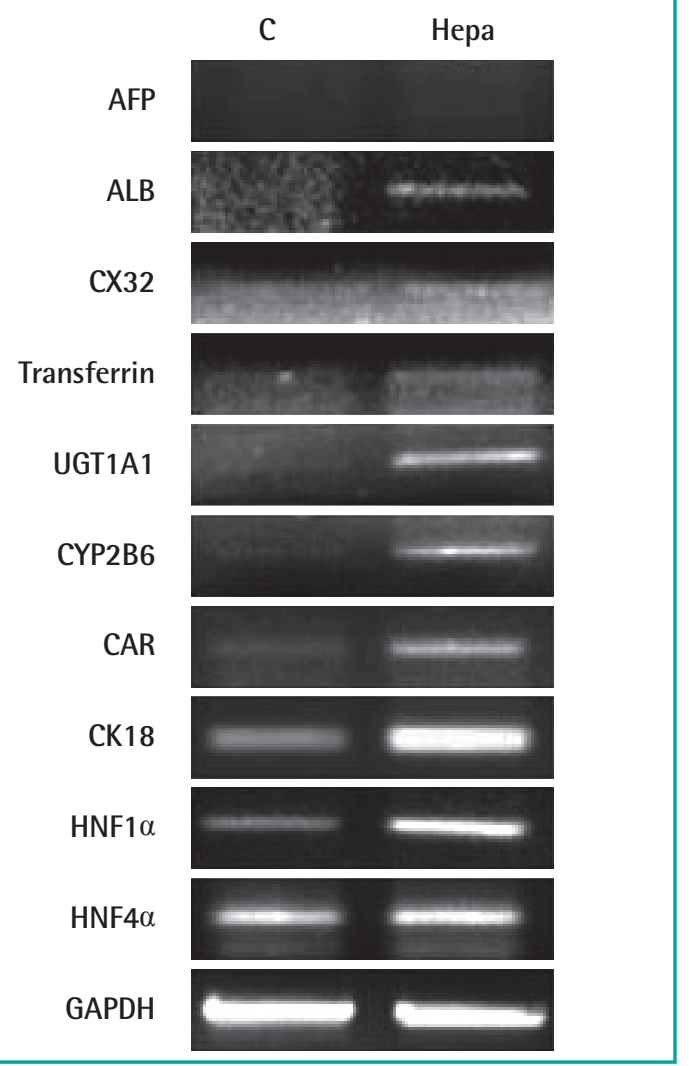

HTASCs (Fig. 4).

\section{Functional characterization of HTASCderived hepato- cyte-like cells}

Differentiation efficiency was also evaluated using functional tests such as PAS staining and detecting of albumin secretion level using ELISA. PAS staining showed that HTASCs submitted to the hepatocyte differentiation protocol were able to more specifically store glycogen compared with undifferentiated HTASCs, which displayed a purple color in the cytoplasm of differentiated HTASCs (Fig. 5). ELISA analyses showed that differentiated HTASCs had a significantly higher secreted albumin $(0.15 \pm 0.057 \mu \mathrm{g} / \mathrm{mL})$ than undifferentiated HTASCs $(0.05 \pm 0.021 \mu \mathrm{g} / \mathrm{mL}, \mathrm{P}<0.05)$ (Fig. 6), suggesting that differentiated HTASCs could secrete albumin, which is one of the hepatocyte markers.

\section{DISCUSSION}

Regenerative medicine involves the combination of cells and

\section{Fig. 4. Immunocytochemical analysis}

Immunocytochemical analysis was performed using an anti-albumin antibody on undifferentiated (A) and differentiated (B) human thigh adipose stem cells (HTASCs) $(\times 100)$. Differentiated HTASCs were intensely stained with anti-albumin antibody compared with undifferentiated HTASCs.

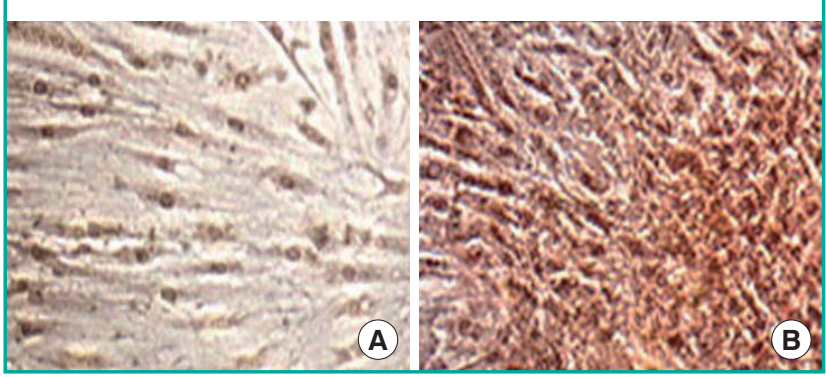

\section{Fig. 5. Functional analysis by PAS staining}

Functional analysis of hepatogenic differentiated human thigh adipose stem cells (HTASCs). Glycogen storage of the cells was detected with periodic acid schiff (PAS) on undifferentiated (A) and differentiated (B) HTASCs $(\times 100)$. PAS staining showed that HTASCs submitted to the hepatocyte differentiation protocol were able to more specifically store glycogen than were undifferentiated HTASCS.

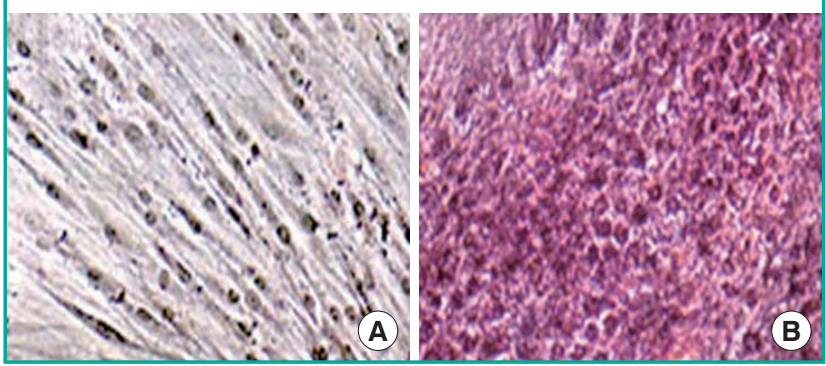




\section{Fig. 6. Functional analysis using ELISA}

Functional analysis of hepatogenic differentiated human thigh adipose stem cells (HTASCS). The albumin secretion level was detected using enzyme-linked immunosorbent assay (ELISA) on undifferentiated (1) and differentiated (2) HTASCs. ELISA analyses showed that differentiated HTASCs could secrete albumin, which is one of the hepatocyte markers.

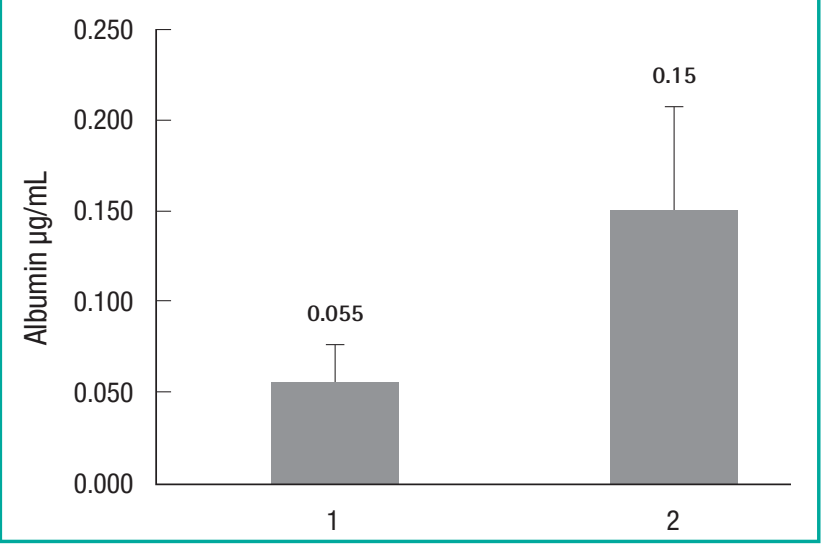

scaffold materials that can be loaded with bioactive factors, ideally resulting in the regeneration or replacement of lost or damaged tissues and organs. Multiple cell sources have been investigated for their possible applicability in tissue engineering. Stem cells that characterize self-renewal and differentiation into multi-lineaged cells are being investigated for tissue engineering. Embryonic stem cells are the most potent stem cells. However, their use is controversial and has major ethical implications [10]. MSCs can be obtained from adults and are widely used because of their differentiation potential. In addition to bone marrow, periosteum [11] and muscle [12] also appear to be sources of MSCs. Particularly, adipose tissue that is commonly obtained using liposuction in plastic surgery is an attractive source of human MSCs because it is a safe and abundant tissue in the body compared with other tissues. In addition, the Korea Food and Drug Administration has granted permission to use self-adiposederived stem cells for transplantation using a minimum process.

Noteably, the fact that plastic surgeons can obtained abundant adipose tissue by liposuction makes the study of ADSCs very convenient. Therefore, many researchers use abundant abdominal adipose tissue as a stem cell source. However, although studies on hepatocyte differentiation using abdominal ADSCs have been reported, reports on hepatocyte differentiation using thigh ADCS have not been documented. Therefore, ADSCs were isolated from human thigh adipose tissue in this study and their morphology, growth potency, phenotypic profile, and capacity for differentiating into various lineages were characterized. In addition, the ability of HTASCs to differentiate into hepatocytes was evaluated.

To recapitulate liver development, a three-step protocol with sequential addition of growth factors (FGF4, EGF, and HGF), cytokines (activin A, OSM), hormones (dexamethasone and insulin), nicotinamide, and DMSO was used in this study $[13,14]$. Activin signaling at a level threefold above baseline dictates that the mesendoderm will move toward the endodermal cell fate [15]. HGF was originally identified and cloned as a morphogenic activator for a wide variety of cells and is known to play an essential role in the development and regeneration of the liver [5]. The foregut endoderm is induced to the hepatocyte lineage by the FGF family produced by the adjacent cardiac mesoderm, which are required to induce a hepatic fate and not the default pancreatic fate [16]. It has been reported that the treatment of cells with OSM, a member of the interleukin-6 cytokine family, increased the cell size of hepatocytes and enhanced cell differentiation and formation of bile canaliculi [17]. Although OSM alone had weak effects on hepatocyte functions, albumin secretion and CYP450 activity were greatly enhanced when combined with nicotinamide or DMSO [18]. DMSO has been known to maintain the functions of adult hepatocytes in vitro [13]. It has been reported that nicotinamide and DMSO remarkably enhanced the emergence of small hepatocytes, and that OSM also synergistically enhanced the selective growth of small hepatocytes and inhibited the growth of blood cell populations [18].

After differentiation, the cells were observed for the morphological changes, gene expression pattern, and functional activities of hepatocyte-like cells derived from HTASCs. Similar to other studies using ADSCs from abdominal adipose tissue $[1,4]$, these cells displayed a hepatocyte-like morphology such as a polygonal shape and cytoplasmic granulation with a more prominent nucleus. The cells also expressed hepatocyte-specific genes including ALB, CX32, transferrin, UGT1A1, CYP2B6, CAR, CK18, HNF1 $\alpha$, and HNF4a, which was consistent with the gene expression pattern from abdominal ADSCs in the report by Seo et al. [4]. Furthermore, these cells exhibited hepatocyte functions such as storage of glycogen, and expression and secretion of albumin, a major protein produced by the hepatocytes. Schmelzer et al. [19] examined the gene expression profile of hepatic cells ranging from the stem cell stage to the mature functional stage. They showed that hepatic stem cells expressed high levels of CK19, low levels of ALB, and no AFP or adult liverspecific proteins. In contrast, hepatoblasts expressed low levels of CK19, elevated levels of ALB, high levels of AFP, and low levels of adult liver-specific proteins.

Taken together, this study successfully isolated human thigh ADSCs, differentiated them into endodermal hepatocytes, and confirmed that the hepatocytes were functional. Therefore, the source of ADSCs is not only abundant abdominal adipose tis- 
sue, but also thigh adipose tissue for cell therapy in liver regeneration and tissue regeneration.

\section{REFERENCES}

1. Banas A, Teratani T, Yamamoto Y, et al. Adipose tissue-derived mesenchymal stem cells as a source of human hepatocytes. Hepatology 2007; 46:219-28.

2. Talens-Visconti R, Bonora A, Jover R, et al. Human mesenchymal stem cells from adipose tissue: differentiation into hepatic lineage. Toxicol In Vitro 2007;21:324-9.

3. Planat-Benard V, Silvestre JS, Cousin B, et al. Plasticity of human adipose lineage cells toward endothelial cells: physiological and therapeutic perspectives. Circulation 2004;109: 656-63.

4. Seo MJ, Suh SY, Bae YC, et al. Differentiation of human adipose stromal cells into hepatic lineage in vitro and in vivo. Biochem Biophys Res Commun 2005;328:258-64.

5. Oh SH, Miyazaki M, Kouchi H, et al. Hepatocyte growth factor induces differentiation of adult rat bone marrow cells into a hepatocyte lineage in vitro. Biochem Biophys Res Commun 2000;279:500-4.

6. Minguell JJ, Erices A, Conget P. Mesenchymal stem cells. Exp Biol Med (Maywood) 2001;226:507-20.

7. Pittenger MF, Mackay AM, Beck SC, et al. Multilineage potential of adult human mesenchymal stem cells. Science 1999;284:143-7.

8. Lee RH, Kim B, Choi I, et al. Characterization and expression analysis of mesenchymal stem cells from human bone marrow and adipose tissue. Cell Physiol Biochem 2004;14: 311-24.

9. Sakaguchi Y, Sekiya I, Yagishita K, et al. Comparison of human stem cells derived from various mesenchymal tissues: superiority of synovium as a cell source. Arthritis Rheum
2005;52:2521-9.

10. Dresser R. Ethical issues in embryonic stem cell research. JAMA 2001;285:1439-40.

11. Nakahara H, Goldberg VM, Caplan AI. Culture-expanded human periosteal-derived cells exhibit osteochondral potential in vivo.J Orthop Res 1991;9:465-76.

12. Asakura A, Komaki M, Rudnicki M. Muscle satellite cells are multipotential stem cells that exhibit myogenic, osteogenic, and adipogenic differentiation. Differentiation 2001;68: 245-53.

13. Kinoshita T, Miyajima A. Cytokine regulation of liver development. Biochim Biophys Acta 2002;1592:303-12.

14. Michalopoulos GK, Bowen WC, Mule K, et al. HGF-, EGF-, and dexamethasone-induced gene expression patterns during formation of tissue in hepatic organoid cultures. Gene Expr 2003;11:55-75.

15. McLean AB, D’Amour KA, Jones KL, et al. Activin a efficiently specifies definitive endoderm from human embryonic stem cells only when phosphatidylinositol 3-kinase signaling is suppressed. Stem Cells 2007;25:29-38.

16. Schwartz RE, Reyes M, Koodie L, et al. Multipotent adult progenitor cells from bone marrow differentiate into functional hepatocyte-like cells. J Clin Invest 2002;109:1291-302.

17. Lazaro CA, Croager EJ, Mitchell C, et al. Establishment, characterization, and long-term maintenance of cultures of human fetal hepatocytes. Hepatology 2003;38:1095-106.

18. Sakai Y, Jiang J, Kojima N, et al. Enhanced in vitro maturation of fetal mouse liver cells with oncostatin $\mathrm{M}$, nicotinamide, and dimethyl sulfoxide. Cell Transplant 2002;11: 435-41.

19. Schmelzer E, Wauthier E, Reid LM. The phenotypes of pluripotent human hepatic progenitors. Stem Cells 2006;24: 1852-8. 


\section{Discussion}

\section{The Possibility of Undifferentiated Human Thigh Adipose Stem Cells Differentiating into Functional Hepatocytes}

Young-Joon Jun

Department of Plastic Surgery, Bucheon St. Mary Hospital, The Catholic University of Korea, Bucheon, Korea

Stem cells are capable of self-renewal and multipotent differentiation into cells that comprise the various organs of the human body beginning in the embryonic period. Stem cells also play a critical role in regeneration of organ or tissue functions throughout the lifetime. Basically, there are two types of stem cells: one is embryonic stem cells derived from blastocytes, and the other is adult stem cells obtained from fully developed adult tissue or placenta. Embryonic stem cells proliferate easily due to excellent self-renewal potency in their undifferentiated state. However, doing so raises ethical questions. Therefore, research on adult stem cells is actively in progress for a new approach to treating as yet unconquered diseases.

Marrow stem cells as a representative of adult stem cells have been used in studies of differentiation into various tissues $[1,2]$. However, harvesting bone marrow is painful to patients and requires multiple samplings to obtain sufficient amounts for clinical use. Therefore, many researchers have begun to seek alternative sources of stem cells. Zuk et al. [3] reported multilineage cells in the extract of adipose tissue that they assumed to be stem cells, and the researchers named them "processed lipoaspirate." Recently, these cells have come to be called adipose tissue-derived stromal cells or adipose tissue-derived stem cells $[4,5]$. These cells can be extracted and separated from adipose tissue, show stable growth and proliferation in a culture environment, and are able to differentiate to various cells like marrow stem cells [6].

Unlike most of studies of adipose tissue-derived stem cells, which have used abdominal fat, the authors used fat from the thigh and differentiated it to morphologically hepatocyte-like cells that showed albumin production and glycogen storage ability, which are distinct characteristics of functional hepatocytes. This finding may provide a foundation for a new method of treatment of hepatic failure.

Recently, differentiation of mesenchymal stem cells has been reported to differ according to its source tissue or the age of the donor [7]. However, the idea that the location of the fat harvest, sex, or age of the donor can influence differentiation characteristics is not yet supported by reliable data. In the authors' paper, human thigh adipose stem cells were able to differentiate into hepatocytes like abdominal adipose tissue-derived stem cells or bone marrow stem cells, but understanding the clear distinction of hepatic differentiation between human thigh adipose stem cells and abdominal adipose tissue-derived stem cells or bone marrow stem cells, and direct human application of these adipose tissue-derived hepatic lineage cells requires further investigation.

\section{REFERENCES}

1. Owen M. Marrow stromal stem cells. J Cell Sci Suppl 1988; 10:63-76.

2. Bianco P, Gehron Robey P. Marrow stromal stem cells. J Clin Invest 2000;105:1663-8.

3. Zuk PA, Zhu M, Mizuno H, et al. Multilineage cells from human adipose tissue: implications for cell-based therapies. Tissue Eng 2001; 7:211-28.

4. Hattori H, Sato M, Masuoka K, et al. Osteogenic potential of human adipose tissue-derived stromal cells as an alternative stem cell source. Cells Tissues Organs 2004;178:2-12.

5. Rodriguez AM, Elabd C, Delteil F, et al. Adipocyte differentiation of multipotent cells established from human adipose tissue. Biochem Biophys Res Commun 2004;315:255-63.

6. Jun YJ, Rhie JW, Choi YS, et al. The effects of adipose derived stem cells on neurogenic differentiation and induction of nerve regeneration. J Korean Soc Plast Reconstr Surg 2006; 33:205-12.

7. Lei H, Yu B, Huang Z, et al. Comparative analysis of mesenchymal stem cells from adult mouse adipose, muscle, and fetal muscle. Mol Biol Rep 2012 Oct 16 [Epub]. http://dx. doi.org/10.1007/s11033-012-2129-3.

Correspondence: Young-Joon Jun

Department of Plastic Surgery, Bucheon St. Mary's Hospital, The Catholic University of Korea,

327 Sosa-ro, 327 beon-gil, Wonmi-gu, Bucheon 420-717, Korea

Tel: +82-32-340-2095, Fax: +82-32-340-2666, E-mail: psdoc@korea.com

No potential conflict of interest relevant to this article was reported.

Received: 30 Oct 2012 Revised: 31 Oct 2012 Accepted: 1 Nov 2012

pISSN: 2234-6163・ elSSN: 2234-6171

http://dx.doi.org/10.5999/aps.2012.39.6.600 • Arch Plast Surg 2012;39:600

Copyright (C) 2012 The Korean Society of Plastic and Reconstructive Surgeons

This is an Open Access article distributed under the terms of the Creative Commons Attribution Non-Commercial License (http://creativecommons.org/

licenses/by-nc/3.0/) which permits unrestricted non-commercial use, distribution, and reproduction in any medium, provided the original work is properly cited. 